RESEARCH SEMINAR IN INTERNATIONAL ECONOMICS

Department of Economics

The University of Michigan

Ann Arbor, Michigan 48109-1220

SEMINAR DISCUSSION PAPER NO. 277

The Possibility of Factor Price Equalization, Revisited

by

Alan V. Deardorff

March 1991

SUMNER AND LAURA

FOSTER LIBRARY

JN 101991 



\title{
The Possibility of Factor Price Equalization, Revisited*
}

\author{
by
}

\author{
Alan V. Deardorff
}

The University of Michigan

May 4, 1991

*My thanks to Paul Krugman, who told me, several years ago, that I should get this written quickly before someone beat me to it. I have also received useful comments from Bob Stern and other participants in the Research Seminar in International Economics at Michigan, and from participants at the 10th Annual Conference on International Trade at the University of Western Ontario. 


\title{
ABSTRACT \\ The Possibility of Factor Price Equalization, Revisited
}

by

\author{
Alan V. Deardorff \\ The University of Michigan
}

This paper derives a condition for Factor Price Equalization (FPE) in a HeckscherOhlin Model with arbitrary numbers of goods, factors, and countries. Using Dixit and Norman's (1980) concept of an Integrated World Economy (IWE), two paths in factor space are constructed for any pair of factors. The first is composed of the vectors of these two factors needed to produce world demands for goods in the IWE, arranged in decreasing order of relative factor intensity. The second is composed of the vectors of the factor endowments of the countries, arranged in decreasing order of relative factor abundance. It is shown here that if the latter, factor-endowment, path ever passes above the former, factor-intensity, path, then FPE is impossible. Therefore, FPE requires that, for any pair of factors, factor endowments vary across countries by less than factor intensities vary across industries, in the sense defined by these two paths.

Address correspondence to:

Alan V. Deardorff

Institute of Public Policy Studies

The University of Michigan

440 Lorch Hall

Ann Arbor, MI 48109-1220

May 4, 1991 


\title{
The Possibility of Factor Price Equalization, Revisited
}

\author{
by
}

\author{
Alan V. Deardorff \\ The University of Michigan
}

\section{Introduction}

Much depends, in modern international trade theory, on whether prices of factors are equalized internationally. With factor price equalization (FPE), industries in different countries with identical, constant-returns-to-scale technologies use identical techniques of production, and the analysis of trade and production is greatly simplified. ${ }^{1}$ Even when there are elements of increasing returns to scale, Helpman and Krugman (1985) have gotten great milage out of the assumption of FPE in simplifying otherwise intractable problems. In contrast, without FPE, trade patterns are perhaps more starkly delimited, ${ }^{2}$ but the different techniques of production used in different countries make comparisons across them much more difficult. ${ }^{3}$ As a contribution, therefore, to understanding the presence or absence of FPE, this paper presents a necessary condition for FPE, stated in terms of the allocation of factor endowments across any number of countries relative to the demands for, and the factor intensities of, any number of goods.

\footnotetext{
${ }^{1}$ For example, the factor content version of the Heckscher-Ohlin Theorem, introduced to the theoretical literature by Vanek (1968) and to the empirical literature by Leamer (1980), depends in its simplest form on the assumption of FPE.

${ }^{2}$ See Deardorff (1979).

${ }^{3}$ In Deardorff (1982), for example, I was able to prove generalizations of both the factorcontent and commodity versions of the Heckscher-Ohlin Theorem even in the absence of FPE. Without FPE, however, the measurement of factor intensity for these purposes becomes cumbersome.
} 
Our knowledge of the conditions for FPE has evolved over the years. Samuelson (1949) identified the crucial condition for FPE in a two factor model - that the two countries should produce at least two goods in common-and he recognized that this in turn requires that countries' factor endowments differ by less than the factor intensities of the industries. With the addition of more than two goods, he suggested (p. 192) that "if anything, it increases the likelihood of complete factor-price equalization" on the grounds that if factor intensities of the added goods are more extreme than those of the goods you start with, then they make it possible for incomplete specialization even by countries with very different factor endowments.

Johnson (1967) formalized Samuelson's contention that the likelihood of FPE grows with the number of goods, which he demonstrated by means of the relationships that must hold between factor prices and factor proportions in various industries. ${ }^{4}$ Then Vanek and Bertrand (1971) approached the problem from a different angle, looking at how preferences for consumption interact with factor intensities and endowments to determine, even when FPE is possible, whether it actually occurs. They provided an ingenious geometric argument in three, four, and even higher dimensions to show that the likelihood of FPE grows with the number of goods. ${ }^{5}$

Perhaps the most useful and enlightening approach to FPE, though, and the one that I will build upon here, was presented by Dixit and Norman (1980, pp. 110-122). They spoke in terms of an "integrated world economy" (IWE), in which both factors and goods

${ }^{4}$ Johnson was responding to Land (1957), who had asserted that additional goods would make FPE very difficult to obtain, since prices would have to be coincidentally alligned so as to make production of all goods possible. Land was ignoring the endogeneity of these prices in the world economy.

${ }^{5}$ Much more recently, Deardorff and Courant (1990) have argued that the introduction of nontraded goods into an otherwise standard Heckscher-Ohlin model reduces the likelihood of FPE. 
are perfectly mobile across countries. ${ }^{6}$ In an IWE the world as a whole attains an equilibrium with a single set of prices of goods, prices of factors, and techniques of production, and with certain equilibrium quantities of all goods demanded on world markets. Then in the same world but witr. immobile factors, if it is possible to allocate factors within countries to industries, using the techniques of production of the IWE, in such a way as to duplicate the world outputs of the IWE, then FPE is possible and this allocation is one that could arise with FPE. If it is not possible to allocate the given factor endowments in this way, then FPE is not possible.

With two factors, two goods, and two countries, this formulation leads to the particularly simple visual representation of FPE factor allocations shown in Figure $1 .^{7}$ It shows a box diagram, the dimensions of which are $\mathrm{L}$ and $\mathrm{K}$, the world factor endowments of labor and capital. Letting the lower-left corner at $\mathrm{O}_{1}$ be the origin for measuring factor endowments of country 1 , and the upper-right corner at $\mathrm{O}_{2}$ be the origin for measuring factor endowments of country 2 , any point in the box describes an allocation of the world's factor endowments between the two countries.

Into this box are introduced the techniques of producing the two goods, $\mathrm{X}_{1}$ and $\mathrm{X}_{2}$, in the equilibrium of the IWE. These appear as the rays from the two origins with slopes $r_{1}$ and $\mathrm{r}_{2}$, equal to the ratios of capital to labor employed in the respective industries in the IWE. These rays form the parallelogram $\mathrm{O}_{1} \mathrm{AO}_{2} \mathrm{~B}$, and this parallelogram, it turns out, includes all of the world's factor allocations that are consistent with FPE. Thus by comparing the size of this parallelogram to the size of the box as a whole, one can form a rough idea of how difficult or easy it may be to get FPE. For example, if the two

${ }^{6}$ Samuelson (1949) had also used this device, though without the name or the accompanying diagram, to motivate and explore the conditions for FPE. Helpman and Krugman (1985) have also used it for a variety of problems.

${ }^{7}$ This diagram is often attributed to Lancaster (1957), who used something similar to show that two countries trading with FPE are equivalent to a single closed economy (p. 31). As far as I know, however, Dixit and Norman (1980) were the first to connect the diagram with the IWE and to use it to delineate the factor allocations consistent with incomplete specialization and FPE. 
industries had very similar factor intensities, so that the $r_{1}$ and $r_{2}$ rays were close together, then the parallelogram would be a narrow sliver near the diagonal of the box, and FPE would occur only if factor endowments were nearly equally distributed across countries. In contrast, if factor intensities were very different, then the parallelogram might occupy almost the whole box, and one could find FPE across counties with very different factor endowments.

These, of course, are conclusions one could also have reached as well by looking at the diversification cone. The box diagram of Figure 1 is an improvement here primarily by showing how the two countries fit together.

With more goods, however, the diagram comes into its own, though still with only two countries. Suppose now that there is a third good. We could again draw the factor intensity rays of the IWE into a box such as Figure 1, but now there would be three of them and only the outermost would be needed to define the diversification cone. Thus in Figure 2 I have drawn a world factor box with the factor intensity rays for goods 1 and 3 , under the assumption that $r_{1}>r_{2}>r_{3}$. These again form the parallelogram $O_{1} A O_{2} B$, which is the intersection of the two countries' diversification cones. However, as Dixit and Norman (1980, p. 120) have emphasized, it is no longer true that FPE holds throughout this parallelogram.

To see this, let $X_{1}, X_{2}$, and $X_{3}$ be the quantities of the three goods demanded on the world market in the IWE, and let $v_{1}, v_{2}$, and $v_{3}$ be the vectors of factors needed to produce these quantities using the techniques of the IWE. Since these vectors of factors must exhaust the world endowments, if placed end to end in the box diagram they will extend from one origin to the other. I have drawn them into the box in this fashion twice, once in decreasing order of capital intensity, $\mathrm{v}_{1} \mathrm{v}_{2} \mathrm{v}_{3}$, and again in increasing order of capital intensity, $v_{3} v_{2} v_{1}$. These two paths of vectors necessarily follow the $r_{1}$ and $r_{3}$ rays for goods 1 and 3 , as shown. 
It is only within the portion of the box bounded by these two paths, the hexagonal area $\mathrm{O}_{1} \mathrm{v}_{1} \mathrm{v}_{2} \mathrm{O}_{2} \mathrm{v}_{2} \mathrm{v}_{3}$, that an equilibrium with FPE can occur. To see this, consider a point such as $Z$, inside the two diversification cones but above the path $v_{1} v_{2} v_{3}$. At such a point both countries are capable of keeping both factors fully employed using the three available techniques, but only by producing too much of two of the goods. Country 1 , for example, must use more than the vector $v_{1}$ in industry one, or else it would have too much capital per worker left over to be fully employed in the more labor intensive industries 2 and $3 .^{8}$

Thus it is not enough that countries have their endowments inside the same diversification cone. In addition they must be far enough inside of it to be able to produce the quantities of goods demanded on the world market. In the case shown in Figure 2, the danger is that if both countries are too near the opposite sides of the diversification cone, then both will need to produce larger quantities of goods of extreme factor intensity than are demanded on the world market. Correspondingly, the output of the good of intermediate factor intensity will be too small.

This technique can easily be extended to additional goods. Let there be $\mathrm{n}$ goods, $j=1, \ldots, n$. Define $X_{j}$ for each good to be the quantities demanded on the world market in the IWE, and define $v_{j}=\left(l_{j}, k_{j}\right)$ as the vectors of labor and capital needed to produce these quantities using the techniques of the IWE. Again these vectors could be laid end-to-end in a box like Figure 2 and they would reach exacly from $\mathrm{O}_{1}$ to $\mathbf{O}_{2}$. By arranging them first in decreasing order of capital intensity (as measured by the ratio $r_{j}=k_{j} / h_{j}$ ), and then a second time in increasing order of capital intensity, two paths can be constructed between which lie all possible allocations of two countries' factor endowments that are consistent with FPE. The space between these two paths, which I have not drawn here, will have

${ }^{8}$ This can be verified geometically by drawing lines parallel to $\mathrm{v}_{2}$ and $\mathrm{v}_{3}$, down and to the left from point Z. See Dixit and Norman (1980, p. 116-117). 
roughly the shape of a lens. All of this has been shown, or at least suggested, by Dixit and Norman (1980, p. 117).

What then if there are more than two countries and more than two factors, as well as more than two goods? This brings me to the main point of this paper. I will now focus on just one of the two paths of factor intensity vectors just described, defined for any pair of factors, which I will continue to call labor and capital. I will compare this "factor intensity path" to a similar path of factor endowment vectors for the countries. My claim is that such a comparison will provide a necessary condition for the possibility of FPE.

In Figure 3, the solid lines form the path of factor intensity vectors $O \mathrm{v}_{1} \mathrm{v}_{2} \cdots \mathrm{v}_{6}$, drawn in decreasing order of capital intensity for six industries. In addition, vectors $\mathrm{V}_{\mathrm{i}}=\left(\mathrm{L}_{\mathrm{i}}, \mathrm{K}_{\mathrm{i}}\right)$ of factor endowments are drawn for each of five countries. These are also drawn end-to-end, in decreasing order of relative capital abundance, as measured by the capital labor ratio $R_{i}=K_{i} / L_{i}$. They form the dotted path $O V_{1} V_{2} \ldots V_{5}$. Assuming that these constitute all of the industries and countries of the world, then the two paths must extend from the origin to the same point $E$, which represents world factor endowments of these two factors.

My claim is that if the endowment path ever passes above the intensity path, as it does in Figure 3 in the neighborhood of point $\mathrm{V}_{3}$, then FPE is impossible. That is,

Proposition: A necessary condition for FPE is that, for any pair of factors, the factor endowment path must be at all points on or below the factor intensity path.

This condition is the many-country, many-factor analogue of the endowment point being within the parallelogram in Figure 1 and within the hexagonal area in Figure 2.

More formally, one can define FPE in terms of the possibility of allocating production of $n$ goods using $l$ factors across $m$ countries as follows: 


\section{Definition (Factor Price Equalization):}

FPE: There exist $\lambda_{i j} \geq 0, i=1, \ldots, m ; j=1, \ldots, n$, such that

$$
\begin{aligned}
& \sum_{i=1}^{m} \lambda_{i j}=1 \quad j=1, \ldots, n \\
& \sum_{j=1}^{n} \lambda_{i j} v_{h j}=v_{h i} \quad i=1, \ldots, m ; h=1, \ldots, 1
\end{aligned}
$$

where $V_{h i}$ is the endowment of factor $h$ in country $i$,

$v_{h j}$ is the amount of factor $h$ needed to produce the world output of good $j$ in the IWE, and $\lambda_{i j}$ is the fraction of world output of good $j$ produced in country $i$.

In order to derive the implications of paths like those in Figure 3 for FPE, it is necessary first to express those paths mathematically. To that end, I narrow attention to any two of the possibly many factors, identifying them arbitrarily as labor, L, and capital, K. Let $\mathrm{L}_{\mathrm{i}}=\mathrm{V}_{\mathrm{Li}}$ and $\mathrm{K}_{\mathrm{i}}=\mathrm{V}_{\mathrm{ki}}$ be the endowments of these two factors in country $\mathrm{i}$, and let $\mathrm{l}_{\mathrm{j}}=\mathrm{v}_{\mathrm{Lj}}$ and $\mathrm{k}_{\mathrm{j}}=\mathrm{v}_{\mathrm{Kj}}$ be the amounts of labor and capital needed to produce the world output of good $j$ in the IWE. I then define $I(L)$, for any level of labor, $L$, as the index of the last country to be added to the endowment path $\mathrm{OV}_{1} \mathrm{~V}_{2} \ldots$ as one moves to the right along it to position L:

$$
I(L): \quad \sum_{i=1}^{I(L)-1} L_{i}<L \leq \sum_{i=1}^{I(L)} L_{i}
$$

For example, in Figure 3 for the level of $L$ directly below the first intersection of the two paths, $I(L)=3$. Likewise, noting the weak inequality in (1), for $L$ directly below a kink of the path such as at $V_{2}, I(L)=2$. Using $I(L)$, I can now formally define the endowment path shown in Figure 3: 


$$
K(L)=\sum_{i=1}^{I(L)-1} K_{i}+R_{I(L)}\left(L-\sum_{i=1}^{I(L)-1} L_{i}\right)
$$

where $\mathrm{R}_{\mathrm{i}}=\mathrm{K}_{\mathrm{i}} / \mathrm{L}_{\mathrm{i}}$.

Similarly, for the intensity path, $O v_{1} v_{2} \ldots$, I first define $J(L)$ as the last country to be added to the path as one moves along it:

$$
J(L): \quad \sum_{j=1}^{J(L)-1} l_{j}<L \leq \sum_{j=1}^{J(L)} l_{j}
$$

Then the intensity path is

$$
k(L)=\sum_{j=1}^{J(L)-1} k_{j}+r_{J(L)}\left(L-\sum_{j=1}^{J(L)-1} l_{j}\right)
$$

where $\mathrm{r}_{\mathrm{j}}=\mathrm{k}_{\mathrm{j}} \mathrm{h}_{\mathrm{j}}$

With this notation, I can now state the formal version of my Proposition:

Theorem: FPE implies $\mathrm{K}(\mathrm{L}) \leq \mathrm{k}(\mathrm{L})$ for all $\mathrm{L}$.

The proof of this result makes use of the following Lemma, which is proved in the Appendix:

Lemma: If $\mathrm{K}\left(\mathrm{L}^{0}\right)>\mathrm{k}\left(\mathrm{L}^{0}\right)$ for some $\mathrm{L}^{0}$, then there exists a number of countries, $\mathrm{I}^{1}$, and a corresponding quantity of labor,

$$
\mathrm{L}^{1}=\sum_{\mathrm{i}=1}^{\mathrm{I}^{1}} \mathrm{~L}_{\mathrm{i}}
$$

such that

$$
\mathrm{K}\left(\mathrm{L}^{1}\right)>\mathrm{k}\left(\mathrm{L}^{1}\right)
$$


Specifically, using the functions $\mathrm{I}(\mathrm{L})$ and $\mathrm{J}(\mathrm{L})$ defined above;

$$
\begin{array}{ll}
\text { if } & R_{I\left(L^{0}\right)} \geq r_{J\left(L^{0}\right)} \\
\text { then } & I^{1}=I\left(L^{0}\right) \\
\text { else } & I^{1}=I\left(L^{0}\right)-1
\end{array}
$$

What this Lemma says is that, if the endowment path passes above the intensity path for any $L$, then it also passes above it at one of the kinks of the endowment path. That makes it possible to prove the theorem only for these kinks. The Lemma also, in its last part, allows one to identify where the relevant kink is. If the endowment path is steeper than the intensity path where it passes above it, then one can find a kink that is also above it by moving to the right. Otherwise one must move to the left. All of this may be obvious from the diagram by itself, but it is proven formally in the Appendix.

With this preparation, I can proceed to the proof of the Theorem.

\section{Proof of Theorem:}

Suppose that FPE holds but that, contrary to the Theorem, $K\left(L^{0}\right)>k\left(L^{0}\right)$ for some $\mathrm{L}^{0}$. Then from the Lemma there must exist a number of countries, $\mathrm{I}^{1}$, and an associated quantity of labor, $\mathrm{L}^{1}$, such that

$$
\mathrm{K}^{1} \equiv \mathrm{K}\left(\mathrm{L}^{1}\right)>\mathrm{k}\left(\mathrm{L}^{1}\right)
$$

Consider any division of outputs across countries, $\lambda_{\mathrm{ij}} \geq 0$, such that $\sum_{\mathrm{i}=1}^{\mathrm{m}} \lambda_{\mathrm{ij}}=1$ for all $\mathrm{j}$, and define

$$
\lambda_{j}^{1} \equiv \sum_{i=1}^{1} \lambda_{i j}
$$

as the fraction of output $\mathrm{j}$ produced in the group of countries $1, \ldots, \mathrm{I}^{1}$. 
The total amounts of capital and labor employed in that group of countries are

$$
\begin{aligned}
& \tilde{\mathrm{K}}^{1}=\sum_{j=1}^{n} \lambda_{j}^{1} k_{j} \\
& \tilde{L}^{1}=\sum_{j=1}^{n} \lambda_{j}^{1} l_{j}
\end{aligned}
$$

I now show that, if $\tilde{L}^{1}=\mathrm{L}^{1}$, then

$$
\tilde{\mathrm{K}}^{1}<\mathrm{K}^{1}
$$

so that no such division of outputs is consistent with full employment of these two factors in this group of countries. This contradiction will establish the Theorem. To show (8), I start with (5) and proceed as follows using (4), (7), (8), and various regroupings of terms: 


$$
\begin{aligned}
& \mathrm{K}^{1}>\mathrm{k}\left(\mathrm{L}^{1}\right) \\
& =\sum_{j=1}^{J\left(L^{1}\right)-1} k_{j}+r_{J\left(L^{1}\right)}\left(L^{1}-\sum_{j=1}^{J\left(L^{1}\right)-1} l_{j}\right) \\
& =\sum_{j=1}^{n} \lambda_{j}^{1} k_{j}+\sum_{j=1}^{J\left(L^{1}\right)-1} k_{j}-\sum_{j=1}^{n} \lambda_{j}^{1} k_{j} \\
& +\frac{k_{J\left(L^{1}\right)}}{l_{J\left(L^{1}\right)}}\left(\sum_{j=1}^{n} \lambda_{j}^{1} l_{j}-\sum_{j=1}^{J\left(L^{1}\right)-1} l_{j}\right) \\
& =\sum_{j=1}^{n} \lambda_{j}^{1} k_{j}+\sum_{j=1}^{J\left(L^{1}\right)-1}\left(1-\lambda_{j}^{1}\right) k_{j}-\sum_{j=J\left(L^{1}\right)}^{n} \lambda_{j}^{1} k_{j} \\
& -\frac{k_{J\left(L^{1}\right)}}{l_{J\left(L^{1}\right)}}\left(\sum_{j=1}^{J\left(L^{1}\right)-1}\left(1-\lambda_{j}^{1}\right) l_{j}\right)+\frac{k_{J\left(L^{1}\right)}}{l_{J\left(L^{1}\right)}}\left(\sum_{j=J\left(L^{1}\right)}^{n} \lambda_{j}^{1} l_{j}\right) \\
& =\sum_{j=1}^{n} \lambda_{j}^{1} k_{j}+\sum_{j=1}^{J\left(L^{1}\right)-1}\left(1-\lambda_{j}^{1}\right) l_{j}\left(\frac{k_{j}}{l_{j}}-\frac{\left.k_{J(L}{ }^{1}\right)}{\left.l_{J(L}{ }^{1}\right)}\right) \\
& +\sum_{j=J\left(L^{1}\right)}^{n} \lambda_{j}^{1} 1_{j}\left(\frac{k_{J\left(L^{1}\right)}}{l_{J\left(L^{1}\right)}^{1}}-\frac{k_{j}}{l_{j}}\right) \\
& >\sum_{j=1}^{n} \lambda_{j}^{1} k_{j} \\
& =\tilde{\mathbf{K}}^{1}
\end{aligned}
$$

The last inequality follows from the ordering of $j$, according to which $r_{j} \geq r_{J\left(L^{1}\right)}$ for all $\mathrm{j}<\mathrm{J}\left(\mathrm{L}^{1}\right)$ and $\mathrm{r}_{\mathrm{j}} \leq \mathrm{r}_{\mathrm{J}\left(\mathrm{L}^{1}\right)}$ for all $\mathrm{j}>\mathrm{J}\left(\mathrm{L}^{1}\right)$. This completes the proof of the Theorem. 


\section{Discussion}

This result gives analytical content to the idea from the $2 \times 2 \times 2$ Heckscher-Ohlin Model that FPE requires factor endowments to differ across countries by less than factor intensities differ across industries. With only two goods and two countries, this merely means that the endowments must lie in the same diversification cone. That is, the difference in endowment ratios of the two countries must be literally smaller than the difference in factor intensity ratios of the two industries. With additional goods this simple result no longer holds, as was seen in Figure 2, and with additional countries and factors the requirements of FPE become even more stringent, as was shown here. It is now necessary to compare not only the extremes of factor endowments with the extremes of factor intensities, but also to account for differences in the distribution of both endowments and intensities for goods and countries that are not extreme.

For any pair of factors, the comparison of the two paths in the Theorem does this. For example, a path of factor intensity rays, such as that drawn in Figure 3, would be a straight line from the origin all the way to point $\mathbf{E}$ if the intensities did not differ across industries. Thus the extent to which this path is bowed up, above the straight line from 0 to $\mathrm{E}$, shows the extent to which intensities differ across industries. Likewise, the same interpretation applies also to the shape of the endowment path. Thus if the intensity path lies everywhere on or above the endowment path, as the Theorem says is needed for FPE, then the intensity path must everywhere be bowed by more than the endowment path. The differences among intensities must therefore be greater, in this sense, than the differences among endowments.

I have deliberately not attempted here to draw conclusions about the "likelihood" of FPE. Such conclusions are often difficult to interpret in any case, and in this case they would require a prior sense of the likelihood, in the real world, of various distributions of factor intensities, factor endowments, and demands for goods. What is really needed is to measure these distributions and to match them against the requirement of the Theorem. 
However, since the theorem deals with factor intensities and demands as they would appear in the Integrated World Economy, and since we certainly do not observe that kind of equilibrium in the world, that empirical exercise cannot be done.

Nonetheless, my own impression, based on the result of this paper, is that the condition for FPE is more stringent than we may have previously thought. Even the smallest violation of the condition in the Theorem, anywhere along the factor endowment and intensity paths, will cause FPE to break down. And this needn't happen for all factors, but only for any pair of them. Therefore, I believe that we should take more seriously than many have often done the properties of the Heckscher-Ohlin model when FPE does not obtain. In particular, empirical tests of the model should rest on versions of the theory that allow for specialization, such as in Deardorff (1982), rather than on the much stronger but more restrictive versions that assume FPE. For example, I do not view the evidence against the Heckscher-Ohlin Theorem presented by Bowen, Leamer, and Sveikauskus (1987) to be persuasive, since they test only a very restrictive and FPE-based factor-content version of that result. 


\section{Appendix}

To establish the Lemma that was used in the text, it is necessary first to show concavity of $k(L)$ in (4).

Concavity of $\mathbf{k}(\mathrm{L})$ : For any $\mathrm{L}^{0}, \mathrm{~L}^{1} \epsilon[0, \mathrm{~L}]$

$$
k\left(L^{1}\right) \leq k\left(L^{0}\right)+\frac{k_{J\left(L^{0}\right)}}{l_{J\left(L^{0}\right)}}\left(L^{1}-L^{0}\right)
$$

\section{Proof:}

$$
\begin{aligned}
& \text { If } \mathrm{L}^{1}>\mathrm{L}^{0} \text {, then } \\
& k\left(L^{1}\right)=\sum_{j=1}^{J\left(L^{1}\right)-1} k_{j}+\frac{k_{J}\left(L^{1}\right)}{l_{J\left(L^{1}\right)}}\left(L^{1}-\sum_{j=1}^{J\left(L^{1}\right)-1} l_{j}\right) \\
& =\sum_{j=1}^{J\left(L^{0}\right)-1} k_{j}+\sum_{j=J\left(L^{0}\right)}^{J\left(L^{1}\right)-1} \frac{k_{j}}{l_{j}} l_{j}+\frac{k_{J\left(L^{1}\right)}}{l_{J\left(L^{1}\right)}}\left(L^{1}-\sum_{j=1}^{J\left(L^{1}\right)-1} l_{j}\right) \\
& \leq \sum_{j=1}^{J\left(L^{0}\right)-1} k_{j}+\sum_{j=J\left(L^{0}\right)}^{J\left(L^{1}\right)-1} \frac{k_{J\left(L^{0}\right)}}{l_{J\left(L^{0}\right)}} l_{j}+\frac{{ }^{k} J\left(L^{0}\right)}{l_{J\left(L^{0}\right)}}\left(L^{1}-\sum_{j=1}^{J\left(L^{1}\right)-1} l_{j}\right) \\
& =\sum_{j=1}^{J\left(L^{0}\right)-1} k_{j}+\frac{{ }^{k}\left(L^{0}\right)}{l_{J\left(L^{0}\right)}}\left(L^{1}-\sum_{j=1}^{J\left(L^{0}\right)-1} l_{j}\right) \\
& =\sum_{j=1}^{J\left(L^{0}\right)-1} k_{j}+\frac{k_{J\left(L^{0}\right)}}{l_{J\left(L^{0}\right)}}\left(L^{1}-L^{0}+L^{0}-\sum_{j=1}^{J\left(L^{0}\right)-1} l_{j}\right) \\
& =k\left(L^{0}\right)+\frac{k_{J\left(L^{0}\right)}}{l_{J\left(L^{0}\right)}}\left(L^{1}-L^{0}\right)
\end{aligned}
$$

Alternatively, if $\mathrm{L}^{1}<\mathrm{L}^{0}$, then 


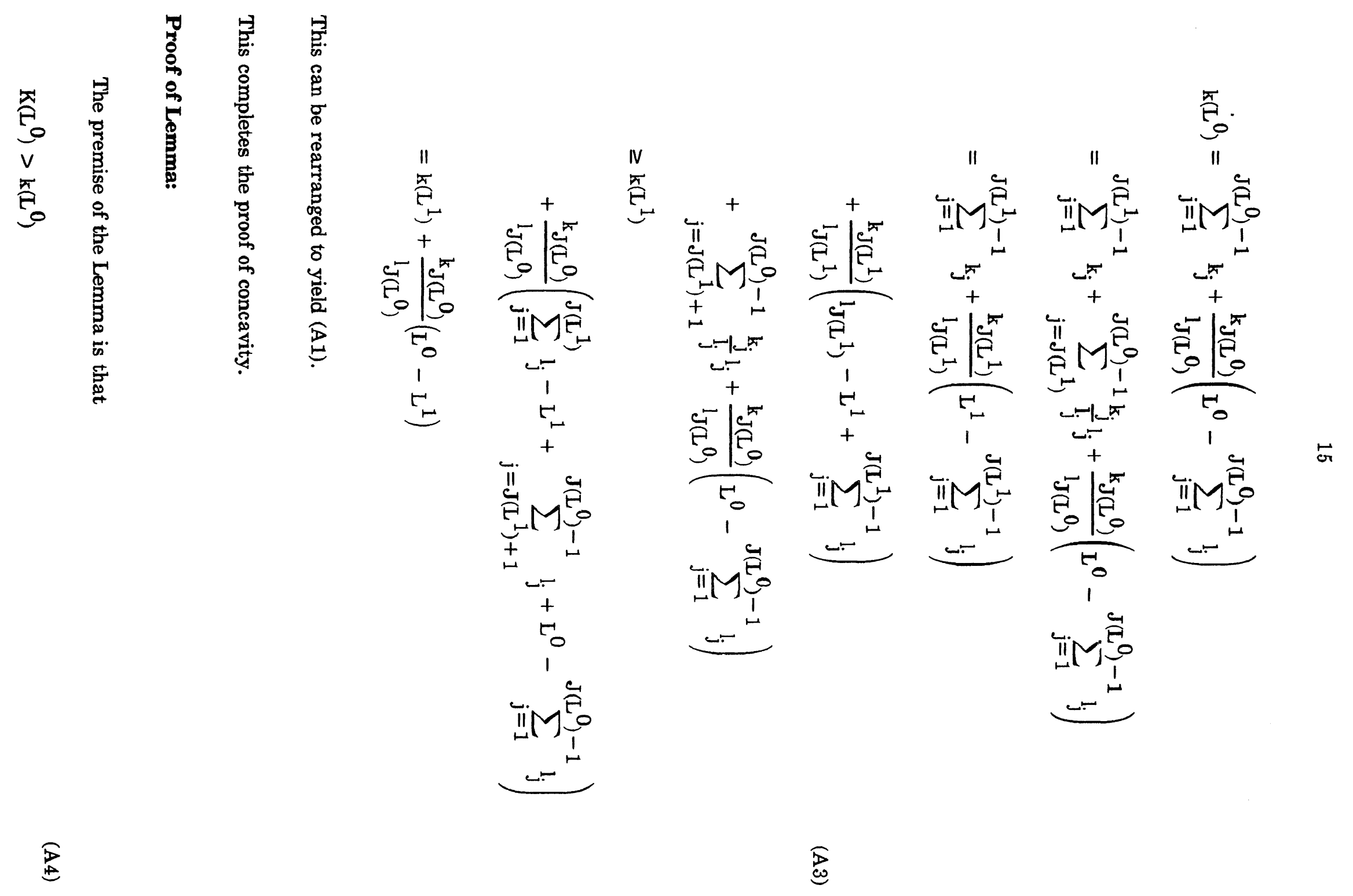


There are two cases to consider, depending on which path is steeper at $L^{0}$.

Case I: $\quad \mathrm{R}_{\mathrm{I}\left(\mathrm{L}^{0}\right)} \geq \mathrm{r}_{\mathrm{J}\left(\mathrm{L}^{0}\right)}$

Thus, by the definitions of $R$ and $r$,

$$
\frac{\mathrm{K}_{\mathrm{I}\left(\mathrm{L}^{0}\right)}}{\mathrm{L}_{\mathrm{I}\left(\mathrm{L}^{0}\right)}} \geq \frac{\mathrm{k}_{\mathrm{J}\left(\mathrm{L}^{0}\right)}}{\mathrm{l}_{\mathrm{J}\left(\mathrm{L}^{0}\right)}}
$$

From the statement of the Lemma, let

$$
\mathrm{I}^{1}=\mathrm{I}\left(\mathrm{L}^{0}\right)
$$

and

$$
\mathrm{L}^{1}=\sum_{\mathrm{i}=1}^{\mathrm{I}^{1}} \mathrm{~L}_{\mathrm{i}} \geq \mathrm{L}^{0}
$$

and thus

$$
\mathrm{I}\left(\mathrm{L}^{1}\right)=\mathrm{I}^{1}
$$

First note that 


$$
\begin{aligned}
K\left(L^{1}\right)-K\left(L^{0}\right)= & \sum_{i=1}^{I\left(L^{1}\right)-1} K_{i}+\frac{K_{I\left(L^{1}\right)}}{L_{I\left(L^{1}\right)}}\left(L^{1}-\sum_{i=1}^{I\left(L^{1}\right)-1} L_{i}\right) \\
& -\sum_{i=1}^{I\left(L^{0}\right)-1} K_{i}-\frac{K_{I\left(L^{0}\right)}}{L_{I\left(L^{0}\right)}}\left(L^{0}-\sum_{i=1}^{I\left(L^{0}\right)-1} L_{i}\right) \\
= & \frac{K_{I^{1}}}{L_{I^{1}}}\left(L^{1}-L^{0}\right)
\end{aligned}
$$

since $I\left(L^{0}\right)=I^{1}=I\left(L^{1}\right)$. Also, from $(A 1)$

$$
k\left(L^{1}\right)-k\left(L^{0}\right) \leq \frac{k_{J\left(L^{0}\right)}}{l_{J\left(L^{0}\right)}}\left(L^{1}-L^{0}\right)
$$

Therefore, using (A4), (A9), (A10), (A5), and (A7),

$$
\begin{aligned}
\mathrm{K}\left(\mathrm{L}^{1}\right)-\mathrm{k}\left(\mathrm{L}^{1}\right) & =\mathrm{K}\left(\mathrm{L}^{1}\right)-\mathrm{K}\left(\mathrm{L}^{0}\right)+\mathrm{K}\left(\mathrm{L}^{0}\right)-\mathrm{k}\left(\mathrm{L}^{0}\right)+\mathrm{k}\left(\mathrm{L}^{0}\right)-\mathrm{k}\left(\mathrm{L}^{1}\right) \\
& >\left(\mathrm{K}\left(\mathrm{L}^{1}\right)-\mathrm{K}\left(\mathrm{L}^{0}\right)\right)-\left(\mathrm{k}\left(\mathrm{L}^{1}\right)-\mathrm{k}\left(\mathrm{L}^{0}\right)\right) \\
& \geq\left(\frac{\mathrm{K}_{\mathrm{I}^{1}}}{\mathrm{~L}_{\mathrm{I}^{1}}}-\frac{\mathrm{k}\left(\mathrm{L}^{0}\right)}{{ }^{1} \mathrm{~J}\left(\mathrm{~L}^{0}\right)}\right)\left(\mathrm{L}^{1}-\mathrm{L}^{0}\right) \\
& \geq 0
\end{aligned}
$$

from which $K\left(L^{1}\right)>k\left(L^{1}\right)$.

Case II: $\quad \mathrm{R}_{\mathrm{I}\left(\mathrm{L}^{0}\right)}<\mathrm{r}_{\mathrm{J}\left(\mathrm{L}^{0}\right)}$

Here

$$
\frac{\mathrm{K}_{\mathrm{I}\left(\mathrm{L}^{0}\right)}}{\mathrm{L}_{\mathrm{I}\left(\mathrm{L}^{0}\right)}}<\frac{\mathrm{k}_{\mathrm{J}\left(\mathrm{L}^{0}\right)}}{\mathrm{l}_{\mathrm{J}\left(\mathrm{L}^{0}\right)}}
$$


Also

$$
\mathbf{I}^{1}=\mathbf{I}\left(\mathrm{L}^{0}\right)-\mathbf{I}
$$

and

$$
L^{1}=\sum_{i=1}^{I^{1}} L_{i}=\sum_{i=1}^{I\left(L^{0}\right)-1} L_{i}<L^{0}
$$

and thus again

$$
\mathrm{I}\left(\mathrm{L}^{\mathbf{1}}\right)=\mathrm{I}^{1}
$$

This time

$$
\begin{aligned}
& \mathrm{K}\left(\mathrm{L}^{1}\right)-\mathrm{K}\left(\mathrm{L}^{0}\right)=\sum_{\mathrm{i}=1}^{\mathrm{I}^{1}-1} \mathrm{~K}_{\mathrm{i}}+\frac{\mathrm{K}_{\mathrm{I}}{ }^{1}}{\mathrm{~L}_{\mathrm{I}} 1}\left(\mathrm{~L}^{1}-\sum_{\mathrm{i}=1}^{\mathrm{I}^{1}-1} \mathrm{~L}_{\mathrm{i}}\right) \\
& -\sum_{i=1}^{I^{1}} K_{i}-\frac{K_{I^{1}+1}}{L_{I^{1}+1}}\left(L^{0}-\sum_{i=1}^{I^{1}} L_{i}\right) \\
& =-K_{I^{1}}+\frac{K_{I^{1}}}{L_{I^{1}}}\left(\sum_{i=1}^{I^{1}} L_{i}-\sum_{i=1}^{I^{1}-1} L_{i}\right) \\
& -\frac{\mathrm{K}_{\mathrm{I}}{ }^{1}+1}{\mathrm{~L}_{\mathrm{I}}{ }^{1}+1}\left(\mathrm{~L}^{0}-\sum_{\mathrm{i}=1}^{\mathrm{I}^{1}} \mathrm{~L}_{\mathrm{i}}\right) \\
& =-\frac{\mathrm{K}_{\mathrm{I}\left(\mathrm{L}^{0}\right)}}{\mathrm{L}_{\mathrm{I}\left(\mathrm{L}^{0}\right)}}\left(\mathrm{L}^{0}-\mathrm{L}^{1}\right)
\end{aligned}
$$

and, from concavity of $k(\mathrm{~L})$, 


$$
k\left(L^{0}\right)-k\left(L^{1}\right) \geq \frac{{ }^{k} J\left(L^{0}\right)}{{ }_{J} J\left(L^{0}\right)}\left(L^{0}-L^{1}\right)
$$

Then, using (A4), (A16), (A17), (A12), and (A14),

$$
\begin{aligned}
K\left(L^{1}\right)-k\left(L^{1}\right) & =K\left(L^{1}\right)-K\left(L^{0}\right)+K\left(L^{0}\right)-k\left(L^{0}\right)+k\left(L^{0}\right)-k\left(L^{1}\right) \\
& \left.>\left(K\left(L^{1}\right)-K\left(L^{0}\right)\right)+\left(k_{\left(L^{0}\right.}\right)-k\left(L^{1}\right)\right) \\
& \geq\left(\frac{k_{J\left(L^{0}\right)}}{l_{J\left(L^{0}\right)}}-\frac{K_{I\left(L^{0}\right)}}{\mathbf{L}_{I\left(L^{0}\right)}}\right)\left(L^{0}-L^{1}\right) \\
& \geq 0
\end{aligned}
$$

from which again $K\left(L^{1}\right)>k\left(L^{1}\right)$. This complete the proof of the Lemma. 


\section{References}

Bowen, Harry P., Edward E. Leamer, and Leo Sveikauskus, "Multicountry, Multifactor Tests of the Factor Abundance Theory," American Economic Review 77, December 1987, pp. 791-809.

Deardorff, Alan V., "Weak Links in the Chain of Comparative Advantage," Journal of International Economics 9, May 1979, pp. 197-209.

Deardorff, Alan V., "The General Validity of the Heckscher-Ohlin Theorem," American Economic Review 72, September 1982, pp. 683-694.

Deardorff, Alan V. and Paul N. Courant, "On the Likelihood of Factor Price Equalization with Nontraded Goods," International Economic Review, August 1990, pp. 589-596.

Dixit, Avinash K. and Victor Norman, Theory of International Trade, London: Cambridge University Press, 1980.

Helpman, Elhanan and Paul R. Krugman, Market Structure and Foreign Trade, Cambridge, MA: MIT Press, 1985.

Johnson, Harry G., "The Possibility of Factor-Price Equalisation when Commodities Outnumber Factors," Economica 34, August 1967, pp. 282-288.

Lancaster, Kelvin, "The Heckscher-Ohlin Trade Model: A Geometric Treatment," Economica 24, February 1957, pp. 19-39.

Land, A. H., "Factor Endowments and Factor Prices," Economica 26, May 1959, pp. 137142.

Leamer, Edward E., "The Leontief Paradox, Reconsidered," Journal of Political Economy 88 , June 1980, pp. 495-503.

Samuelson, Paul A., International Factor Price Equalisation Once Again, " The Economic Journal, June 1949, pp. 181-197.

Vanek, Jaroslav, "The Factor Proportions Theory: The n-Factor Case," Kyklos 4, October 1968, pp. 749-756.

Vanek, Jaroslav and Trent J. Bertrand, "Trade and Factor Prices in a Multi-Commodity World," in Bhagwati, Jones, Mundell, and Vanek, eds., Trade, Balance of Payments and Growth: Papers in International Economics in Honor of Charles P. Kindleberger, Amsterdam: North-Holland, 1971. 


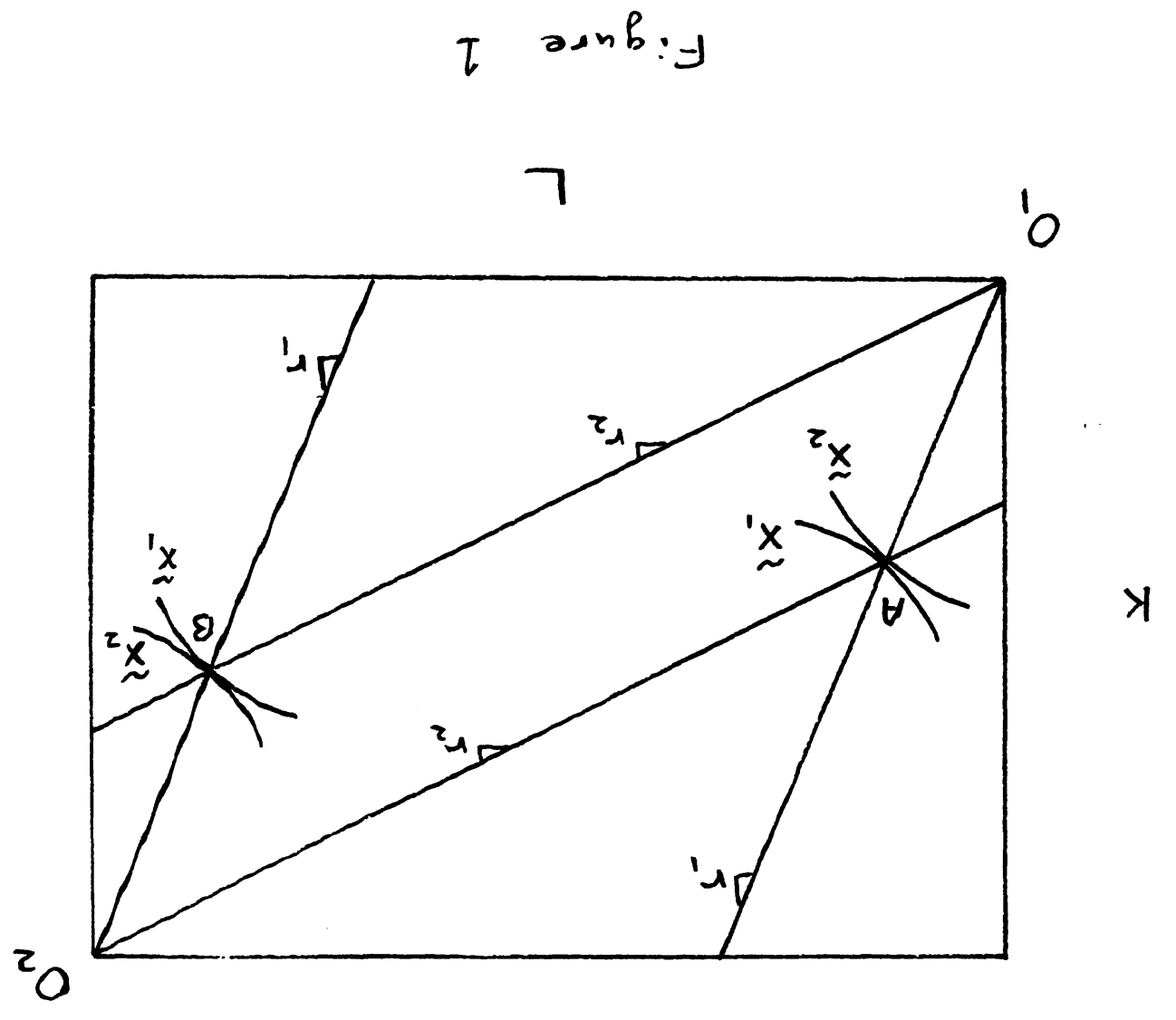




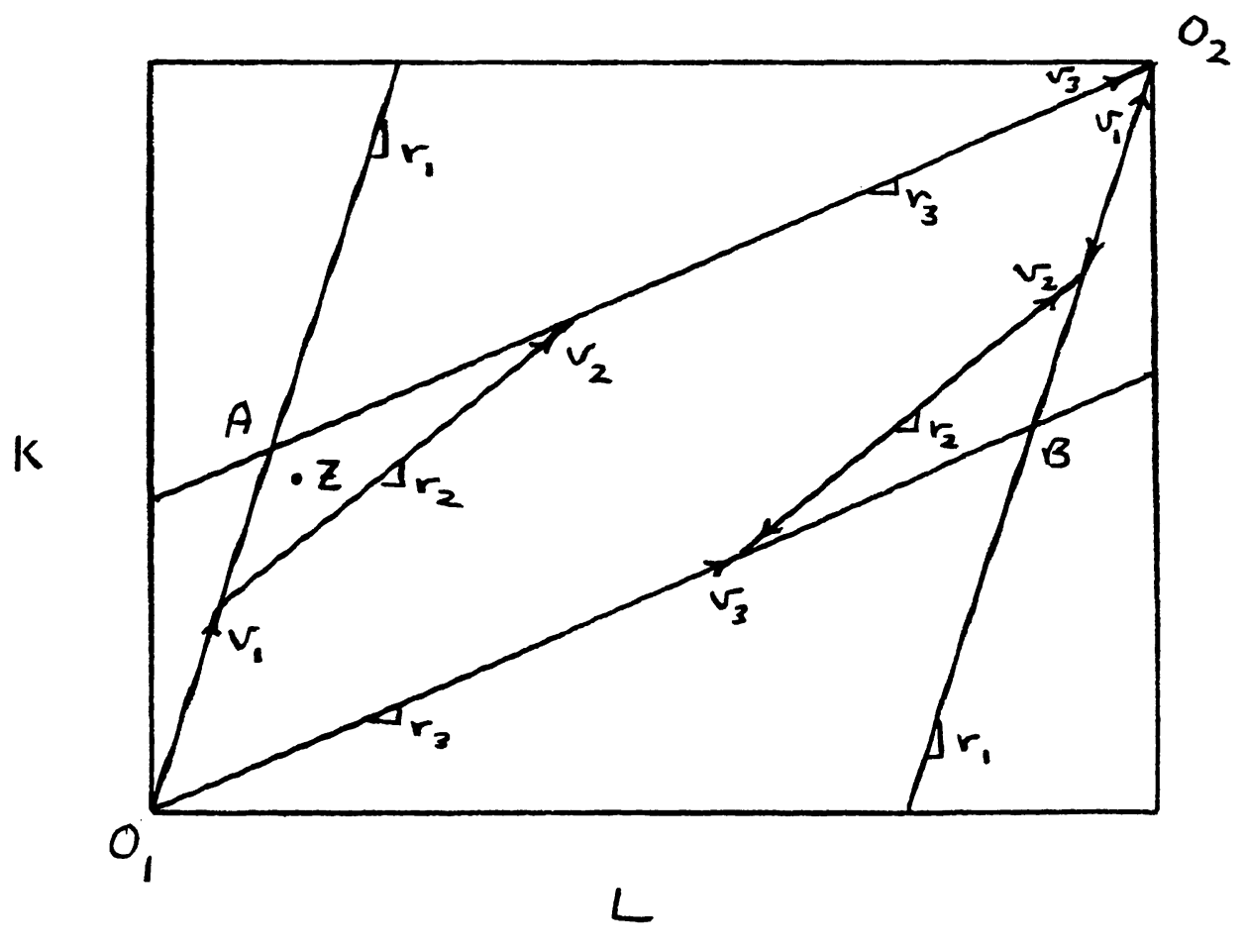

Figure 2 